\title{
Estudo histológico do fígado do escorpião Tityus Bahiensis (Perty)
}

\author{
ADIEL PAES LEME ZAMITH \\ Escola Superior de Agricultura "Luiz de Queiroz" \\ Universidade de S. Paulo —Piracicaba
}

INDICE

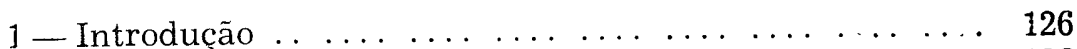

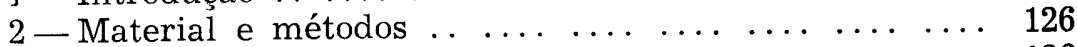

$\begin{array}{lllllllllll} & 3-\text { Morfologia } \ldots & \ldots & \ldots & \ldots & \ldots & \ldots & \ldots & \ldots & \ldots & \ldots\end{array}$

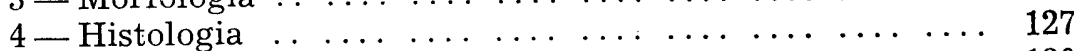

5 —Discussão e conclusão $\ldots \ldots \ldots \ldots \ldots \ldots \ldots$

$\begin{array}{llllllll}6 \text { - Bibliografia consultada } & \ldots & \ldots & \ldots & \ldots & \ldots & \ldots & \ldots\end{array}$ 


\section{INTRODUÇÃO}

Há muitos anos que vimos trabalhando com escorpiões, não só do gênero Tityus como de outros que ocorrem no Brasil. Nestes estudos, chamou-nos a atenção a falta de conhecimento da microscopia dos nossos escorpionídeos, passando assim a estudálos, a começar pela espécie mais abundante em Piracicaba.

\section{MATERIAL E MÉTODOS}

O material foi coletado nos terrenos da Escola Superior de Agricultura "Luiz de Queiroz". Trazidos para o laboratório, os animais foram dissecados após entorpecimento pelo éter, scib uma lupa, em caixa de Petri com fundo de cera e sob Ringer. Com uma tesoura foi cortada tôda a volta do corpo do anirnal, ao longo das pleuras e na região fronteiriça ao post-abdômen, cortado transversalmente o tergum. Em seguida, foi levantada a parte superior do corpo, cortando-se as colunas musculares.

Estando a descoberto o fígado, que enche tôda a parte abdominal, retiramos os órgãos reprodutores com auxílio de urna agulha fina, deixando sòmente o intestino e os canais de Malpighi.

Para a histologia o fígado foi fixado pelo Bouin modificado para inseto e pelo Zenker, durante 6 horas, sem ser retirado do corpo do animal. Em seguida foi feita uma lavagem em água corrente por 12 horas.

Foram feitos cortes longitudinais e transversais com $5 \mathrm{mi}$ cros de espessura, pelo micrótomo də parafina. De cada animal fizemos 10 lâminas, sendo coloridas 5 pela hematoxilina-eos :r. e 5 pelo Mallory. Obtivemos ótimos cortes.

\section{MORFOLOGIA}

Ao levantar a parte superior do exosquêleto, notamos que da região média do diafragma sai para a parte posterior, atravessando todo o abdômen, uma lâmina muscular longitudinal, prêsa à parte ventral do animal e que se liga também à parte dorsal por meio de 5 lâminas perpendiculares, que se distribuem respectivamente nos 2.o, 3.o, 4.o, 5.o e 6.o segmentos. A última lâmina perpendicular é fina, mais delicada do que as outras. A lâmina longitudinal, na parte posterior do abdômen, prende-se à musculatura média ventral do post. abdômen. 
O fígado é uma glândula tubulosa, ramificada, envolvidu por uma membrana fina e transparente, que desce aos bordes por onde passam as colunas musculares, dividindo-a em lóbuios. Porém, esta lobulação não ganha a parte mediana do ór ;ãc. tanto superiormente como inferiormente.

A glândula inteira que enche por completo tôda a caviơade abdominal, apresenta uma coloração parda, amarronzada. Seus lóbulos são pouco visíveis quando ainda no animal. inas retirando-a com cuidado e colocando-a sob Ringer vêm-se us lóbulos anteriores e os posteriores que são menores e mais livres. Os laterais continuam pouco individualizados.

Com muito cuidado, destruindo-se a membrana envolve1:. te e procurando-se abrir caminho por entre a massa hepática, vamos descobrir que o canal digestivo recebe 5 pares de ramificações, sendo que os 4 primeiros pares estão em ângulo ret: corn o intestino e o último par forma mais ou menos um ângulo de $45^{\circ}$ (Fig. 1). Quanto aos seus diâmetros, os três pares medianos possuem uma grossura que equivale quase a do tubo digestivo. $O$ último à metade e o primeiro, colocado próximo to diafragma, bastante fino.

As distâncias que separam estas ramificações entre si são pràticamente iguais. Êstes canais dividem-se dicotômicamente em ramos secundários, que por sua vez dão outros que muitas vêzes já são as últimas ramificações.

Todos os canais do fígado são ligados entre si por um terido conjuntivo frouxo, lacunoso, que, dá a forma maciça ao órgão, respeitando as divisões em grandes lobos revestidos externamente pela membrana diáfana.

No meio dos tubos hepáticos, encontramos ramificações da veia e artéria hepática, bem como dos tubos de Malpighi que não foram retirados.

\section{HISTOLOGIA}

Intestino médio (Fig. 2) - A mucosa é formada por um epitélio, de células altas, cilíndricas ou cuneiformes, de paredes laterais pouco nítidas. Estas células, de espaço em espaço, tomam uma disposição bastante interessante, formando um tufo, comparável a um bulbo de “iridácea". Estas células apresentam um citoplasma vacuolizado na maior parte, sendo, no entanto, nas regiões apicais e basais mais denso, com finas gra- 
nulações basófilas. Medem 60 micros de comprimento por 15 de largura. O núcleo é circular ou oval, com 4,5 micros ostentando um retículo cromático, contendo em seu interior um nucléolo.

De permeio com estas células, vemos outras nitidamente glandulares que aumentam em número à medida que se aproximam das ramificações que formam o órgão hepáticó.

O citoplasma destas células mostra-se repleto de grânulos basófilos, que pela sua quantidade obscurecem o núcleo.

A lâmina própria é fina e assenta-se sôbre uma muscular longitudinal, de fibras estriadas transversalmente.

Ramificações primárias - (Fig. 3) - O intestino médio apresenta quase que a mesma estrutura das suas ramificações, porém, nestas aumentam as células basófilas e começam a aparecer algumas células com bôlhas acidófilas. A lâmina própria continua fina e vai perdendo a base muscular aparecendo raras fibras longitudinais.

Ramificações menores (Fig. 4) - Da segunda ramificação em diante, já se pode considerar como fígado pròpriamente dito. E' observada nestas ramificações a ocorrência de dois tipos de células; células com grânulos basófilos e células que possuem bôlhas acidófilas.

As células nestas ramificações são pràticamente iguais às das primeiras ramificações, porém, levemente menores, atingindo 50 micros de comprimento. O citoplasma continua vacuolizado e mais homogêneo nas extremidades. Contém em sua estrutura bôlhas de vários tamanhos, de natureza acidófila, que parecem ser de lipídeos (coloração amarela ou avermelhada pelo Mallory). A lâmina própria é fina e as fibras musculares desapareceram.

As ramificações seguintes não podem ser acompanhadas em sua sequência, mas vários tubos terminam já na 3a. ramificação. Os tubos menores, isto é, de diâmetros menores, apresentam células mais baixas: 40 a 50 micros de altura por 10 ou 12 de largura. $O$ núcleo coloca-se na parte média basal, mede 5 micros de diâmetro, apresenta um retículo cromático muito nítido, bem como um nucléolo. 


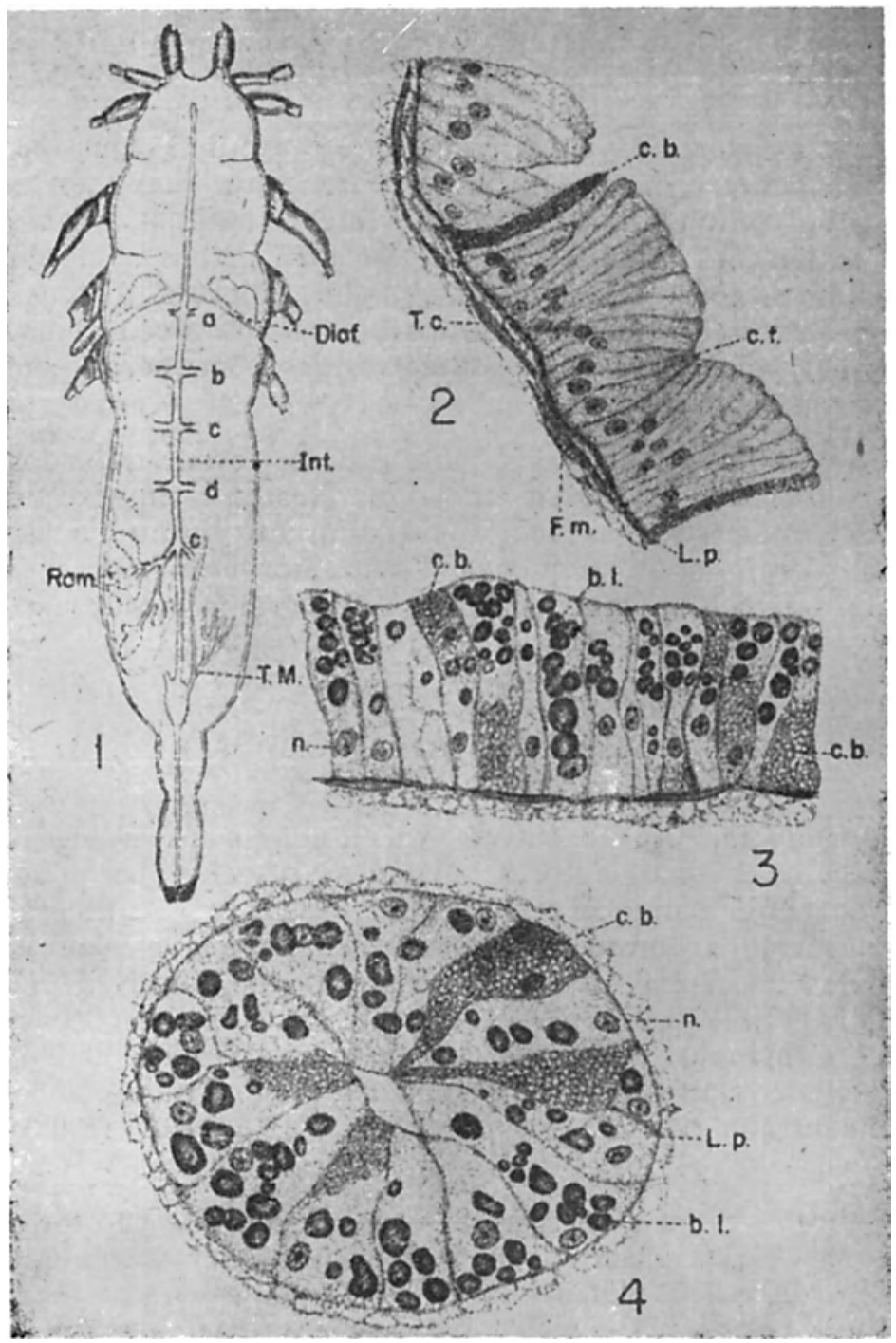

Fig. 1 - Parte inferior do corpo de Tityus bahiensis; Diaf. - dia. fragma; Int. - Tubo intestinal; $a, b, c$, d, o- ramificações primárias do hepato-pâncreas; Ram. - ramificações secundárias e terciarias; T.m. - tubos de Malpighi.

Fig. 2 - Corte longitudinal do intestino médio; c.b. - célula com granulações basófilas; c.f. - células em formação de bulbo de "iridacea"; T.c. - tecido conjuntivo; F.m. - fibra muscular; L.p. - lâmina própria

Fig. 3 - Corte longitudinal da 1.a ramificação; c.b. - célula basófila; b.l. - Bôlhas de lipídeo; n. - núcleo.

Fig. 4 - Corte transversal de um tube firal do hepato-pâncreas; c.b. - célula basófila; n. - núcloo; l.p. - lâmina própria; b.l. bôlhas de lipídeo. 
Uma secção transversal de um tubo terminal, com $100 \mathrm{mi}-$ cros de diâmetro, mostra quase sempre a luz irregularmente aberta, ou completamente fechada. Encontramos 3 a 4 células com granulações basófilas. As células com bôlhas acidófilas apresentam-se tôdas elas com um grande número de bôlhas, que em uma média de 10 células deu 7,5 bôlhas para cada uma. Estas bôlhas variam muito de diâmetro, desde pequenas com 1,5 micros até 8 micros.

Dos animais capturados para estudo, foram deixados alguns pelo espaço de 20 dias em jejum. Nestes, o número de bôlhas de lipídeos (gôtas acidófilas) diminuiu muito e as que permaneceram eram pequenas. Essa observação, parece indicar que tais células têm por função absorver e armazenar matéria graxa.

\section{DISCUSSÃO E CONCLUSÃO}

Morfologia: Na literatura consultada os escorpiões estudados pelos diversos autores são todos pertencentes a família Buthidae englobando alguns gêneros. Quando os autores tratam das colunas musculares perpendiculares que seguram as carapaças do cephalo-torax encontramos em WERNER (1935) e PAVLOVSKY \& ZARIN (1926) que estudaram escorpiões do gênero Centrurus, o número de 6, porém, BORDAS (1907) cita 5 colunas para o Buthus europaeus, concordando com o que foi encontrado para Tityus bahiensis. GUIEYSSE (1908) não faz menção.

Sôbre as ramificações do intestino médio que vão ter ao fígado, nos vários autores encontramos números diversos e também disposição variável.

WERNER (1935) diz: “As quatro anteriores são mais ou ruenos de diâmetros iguais, sòmente a 1a. pouco mais fina que as seguintes. Elas se afastam obliquamente do intestino. $O$ último par (o quinto) desemboca justamente atrás do 4.o, é desenvolvido, muito mais grosso que os precedentes".

GUIEYSSE (1908): "O diâmetro dos tubos é pouco "nais estreito que o do intestino, ligando-se em ângulo reto".

LANKESTER (1904): Apresenta um desenho e em resumida descrição diz que o escorpião apresenta 5 ramificações no intestino e que a última é oblíqua. E' esta descrição que con- 
corda com a que foi vista no Tityus bahienses. Quanto a grossura dos tubos, a descrição de WERNER destoa bastante do qie foi encontrado no T. bahiensis.

Histologia: No epitélio dos tubos componentes do figado é observada a ocorrência de dois tipos de células que já foram chamadas por GUIEYSSE, PAVLOVSKY \& ZARIN como células de fermento, as que apresentam grânulos basófilos e normais, de 1a. e 2a. categoria as que possuem bôlhas acidófilas, sendo estas também chamadas de células absorventes por WERNER. O T. bahiensis é concorde com os outros escorpiões da família Buthidae.

Conclusão: Salvo pequenas divergências na parte morfológica, o que foi observado no escorpião brasileiro T. bahiensis concorda com o que se conhece das espécies de ultra-mar.

\section{BIBLIOGRAFIA CONSULTADA}

BORDAS, L., 1907 - Considérations générales sur le tube digestif des Scorpions (Buthus europaeus L.) Bull. Soc. Zool. Paris. 32. s. 167-169.

BLANCHARD, M. E., 1855 - Des functions du foie chez les Arachnides. C. R. Acad. Sci. Paris XLI. 2, s. 1256.

GUIEYSSE, A., 1908 - Etude des organes digestifs chez le Scorpion. Arch. Anat. microsc. Paris, 10. s. 123-139.

LANKESTER, E. RAY, 1904 - Structure of the Arachnida. Quart. J. Micr. Sci (N. S.) Nr. 190, XLVIII part. 2. s. 165269, 77 Testfig.

PAVLOVSKY, E. N. \& ZARIN, E. J., 1926 - On the Structure and Ferments of the Digestive Organs of Scorpions. Quart J. Micr. Sci. Vol. 70 Pt. II. N. 278. S. 226-262, Taf. 22-23, 7 Textfig.

WERNER, F., 1935 - 5. Band: Arthropoda, IV Abteilung: Arachnoidea, 8. Buch: Scorpiones, Pedipalpi. - Leipzig. 
. 